WARSZAWA 1986

Krzysztof Woźniak

\title{
THE DISCRIMINATION OF CROPS BY USING AIR PHOTOGRAPHY. A CASE STUDY OF THE PŁOCK REGION
}

In Poland's geographical environment we have to do with the following three factors that determine the use of remote sensing techniques in the identification of crops: far-going disintegration of cropland, the mosaic of crops and specificity of the vegetation season. The first factor causes that in order to discriminate the structure of cropland, photographs or their magnifications scaled not less than 1:10000 must be used, as this is already the case where the area of a medium-acreage arable plot (of significantly less than $1 \mathrm{ha}$ ) presented on photograph starts to be less than $1 \mathrm{~cm}^{2}$, making discrimination much more difficult especially when the plot is not square. The mosaic of crops (ten basic crops: rye, wheat, barley, oats, maize, rape, potatoes, sugar beets, clover and grasses) requires the use of more than only one light-sensitive material in photography, if we want to get maximum diversification of crops photographed.

The quality of the image will primarily depend on the electromagnetic reemission and on its spectral structure. This, in turn, will be an outcome of not only the type and species of plants cultivated, but also of the time-related moment in which the photographs were taken. It is self-evident that, as the phenological cycle progresses, there will also change colour and shape of a plant and the density of plant cover in the field, and a very diversiffed photographic image of one and the same crop may be produced. From the viewpoint of photographic usefulness, interesting is the fragment of the vegetation season which will give a fully perceivable cross-section of the cultivated crops. Under the specific Polish conditions, this will be the interval between the turn of April/May and the turn of July/August covering, according to the scientific nomenclature, four phenological corn growing phases: stalk shooting, heading, dairy ripeness, and waxy ripeness. Interregional differences in the occurrence of these various phases cover no more than two weeks. Differences arise due to weather anomalies, too.

Factors that disturb an ideal photographic image of the crop include local environmental conditions, for example, humidity relations in the 
surface layers of the soil, exposure of the field to sun rays, weeds, as well as such phenomena as lodging and laying of crops, and plant diseases. By taking positive of panchromatic photograph as a basis, distortions of the image due to environmental factor may assume the following forms:

- darker phototone due to an increase in the soil humidity level;

- phototone diversification due to differences in the exposure;

- phototone diversification dependent on the type of weeds;

- image stains due to the lodging of crops;

- image blurring and a change in the texture due to laying of crops;

- image stains due to plant diseases.

It is also the type of soil that will influence the phototone or colour of the image. Just as the above-mentioned environmental factors, it may exert a direct impact which can easily be photographed, particularly where the plant cover fails to be too dense, and an indirect one when affecting the growth and quality of crops. The impact of the environmental elements is additionally aided by the effect of agrotechnical factors, such as type and intensity of fertilization as well as agrotechnical jobs, to mention, e.g. grass or clover mowing.

In the light of the above-mentioned facts, discrimination of crops ought to be monitored and supported by an earlier reconnaissance in the field to work out discrimination key on this basis. Statistical data may equally well serve as a supplementary information in this case. Certainly, such a discrimination key cannot be universal by its nature. To make the idea workable it would be necessary to emphasize the sort of light-sensitive materials, the duration of photographing (to be no longer than one phenological phase), and the environmental characteristics to which such a key is referring. In this analysis results of such a process of discrimination have been presented.

Field reconnaissance accompanied air photography operations. Under the field monitoring programme, identification of the actual crops, meteorological and soil humidity measurements as well as surveying of the geographical environment have been carried out in the so-called training areas. As soon as the land had been photographed, a discrimination key was prepared for eight main crops: rye, wheat, barley, oats, rape, potatoes, sugar beets and clover. The key looked like a legend made up of photographic imagery fragments covering the particular crops that had been discriminated and identified in the territory of the training areas. With the discrimination key in hand and field experimentation brought to an end, a cameral discrimination of the whole land under test has been carried out by conventional visual methods.

To arrive at the most appropriate measure of credibility or proba- 
bility for a correct discrimination of crops photographed from the air is not an easy task. Quite natural might seem the measure of this phenomenon by which the acreage of the properly identified crop in air photography is related to the actual acreage of such a crop in the field. But this is not sufficient. A part of the acreage as identified from a photograph might have been misidentified and no account is taken of the size of the area when calculating the said measure. That is why, two measures of credibility or probability are proposed to arrive at the most reliable discrimination of crops. These would include:

coefficient of discrimination 'reliability acconding to the formula:

$$
P_{\mathrm{t}}=\frac{R}{T} 100 \%
$$

wherein: $R$ - acreage of the properly discriminated crop on a photograph; $T$ - total actual acreage of the crop in the field and identification error acconding to the formuła:

$$
B_{1}=\frac{Z-R}{Z} 100 \%
$$

wherein: $Z$ - total acreage of crop as identified on a photograph; $R$ - acreage of the properly discriminated crops on a photograph.

The total coefficient of discrimination reliability was calculated according to the formula:

$$
\bar{P}_{\mathrm{f}}=\frac{\sum_{\mathrm{k}=1}^{\mathrm{n}} R_{\mathrm{k}}}{\sum_{\mathrm{k}=1}^{\mathrm{n}} T_{\mathrm{k}}} 100 \%
$$

and the total indentification error according to the formula:

$$
\bar{B}_{i}=\frac{\sum_{\mathrm{k}=1}^{\mathrm{n}} Z_{\mathrm{k}}-\sum_{\mathrm{k} 1=}^{\mathrm{n}} R_{\mathrm{k}}}{\sum_{\mathrm{k}=1}^{\mathrm{n}} Z_{k}} 100 \%
$$

The area of investigation covered a piece of land situated $20 \mathrm{~km}$ north-east of the town of Plock. This is a flat sort of country cut into two tragments by the narrow and deep Skrwa River valley, and confined by the Vistula valley from the west. Geologically, this is a young formation with a Quaternary cover and with the podsol and fallow soils overlying the loamy substrate. Humidity of the soil ranges from 6 to 18 per cent in the humus layer. Right before photographing there followed intense rainfalls. Weeds, such as camomile (Matricaria chamomilla) and bent grass (Apera spica-venti), used to be found chiefly 

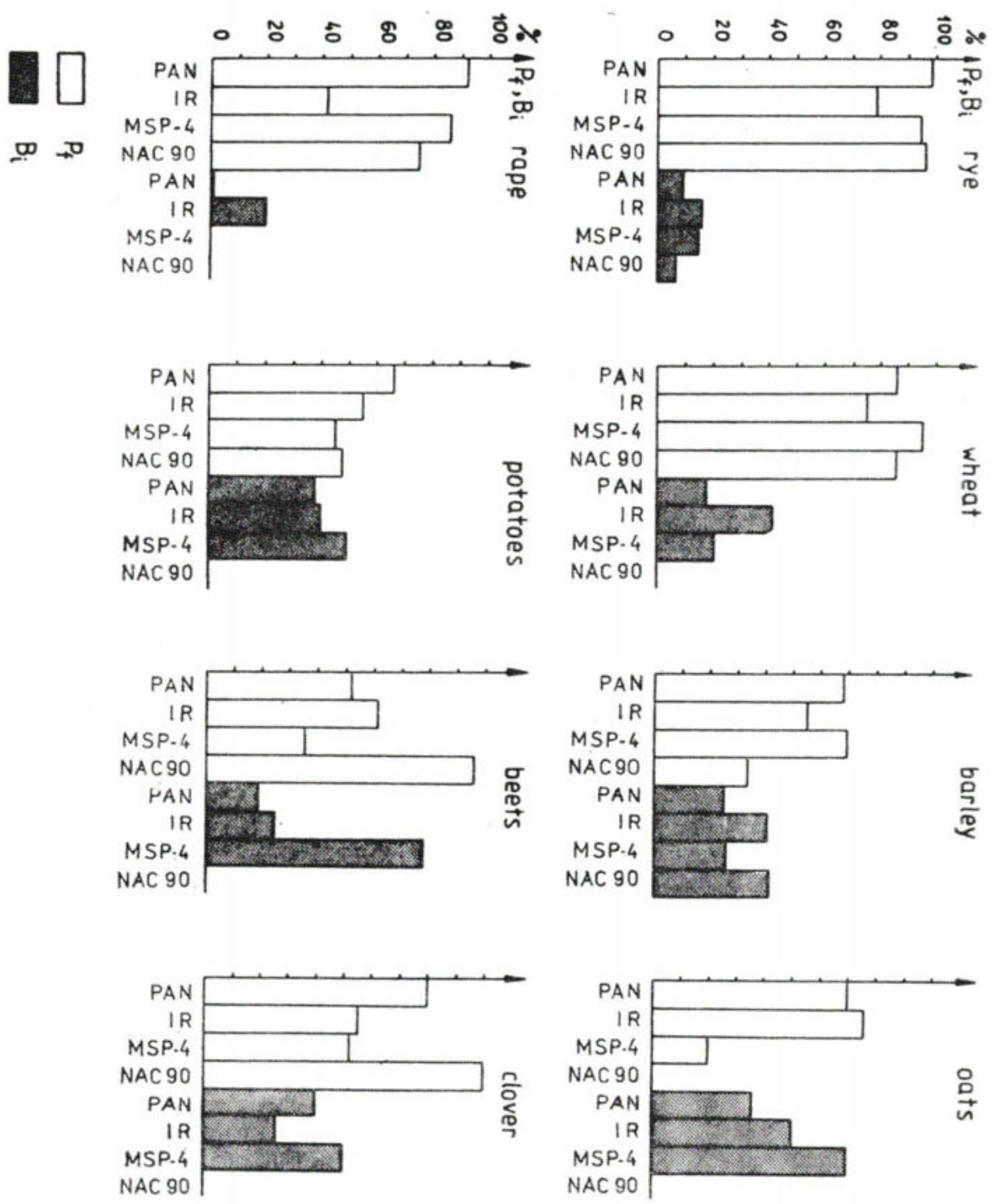

Fig. 1. Reliability structure for the dicrimination of crops on aerial photographs.

among rape and wheat respectively. The area under test is dominated by small-scale commodity production with peasant farms ranging from 5 to 10 hectares in size. There predominates corn growing tendency with a considerable share of root crops.

The analysis of crops on the panchromatic and infrared photographs 
Table 1

Discrimination of crops by using air photography and assessment of the credibility of data thus produced (Plock Area of Investigation, 1978)

\begin{tabular}{|c|c|c|c|c|c|c|c|c|c|c|c|c|c|c|c|c|c|c|}
\hline \multirow{2}{*}{$\begin{array}{l}\text { PHOTOGRA- } \\
\text { PHY }\end{array}$} & \multicolumn{2}{|c|}{ Rye } & \multicolumn{2}{|c|}{ Wheat } & \multicolumn{2}{|c|}{ Barley } & \multicolumn{2}{|c|}{ Onte } & \multicolumn{2}{|c|}{ Rape } & \multicolumn{2}{|c|}{ Potatoes } & \multicolumn{2}{|c|}{ Beets } & \multicolumn{2}{|c|}{ Clover } & \multicolumn{2}{|c|}{ TOTAL } \\
\hline & $\overline{\mathbf{P}}_{f}$ & $\mathbf{B}_{\mathbf{1}}$ & $\mathbf{P}_{\mathbf{r}}$ & $\mathbf{B}_{\mathbf{1}}$ & $\mathbf{P}_{\mathbf{f}}$ & $\mathbf{B}_{\mathbf{i}}$ & $\mathbf{P}_{\mathbf{r}}$ & $\mathbf{B}_{\mathbf{1}}$ & $\mathbf{P}_{\mathbf{r}}$ & $\mathbf{B}_{\mathbf{1}}$ & $\mathbf{P}_{\mathbf{r}}$ & $\mathbf{B}_{\mathbf{1}}$ & $\mathbf{P}_{\mathbf{f}}$ & $\mathbf{B}_{\mathbf{s}}$ & $\mathbf{P}_{\mathbf{t}}$ & $\mathbf{B}_{\mathbf{1}}$ & $\overline{\mathbf{P}_{\mathbf{r}}}$ & $B_{1}$ \\
\hline PAN & 98 & 9 & 86 & 18 & 69 & 24 & 70 & 36 & 92 & 1 & 67 & 38 & 52 & 19 & 81 & 40 & 83 & 10 \\
\hline IR & 78 & 15 & 75 & 42 & 56 & 42 & 76 & 51 & 43 & 20 & 57 & 40 & 63 & 25 & 57 & 25 & 68 & 39 \\
\hline MSP-4 & 95 & 13 & 94 & 21 & 70 & 25 & 21 & 70 & 95 & 0 & 45 & 51 & 36 & 78 & 52 & 50 & 77 & 26 \\
\hline AC-90 & 96 & 7 & 87 & 0 & 33 & 42 & 0 & - & 75 & 0 & 57 & 0 & 92 & 0 & 100 & 0 & 80 & 7 \\
\hline PAI & & & & & & & & & & & & & & & & & & \\
\hline MSP-4 & 99 & 7 & 90 & 9 & 86 & 11 & 62 & 38 & 100 & 0 & 77 & 16 & 64 & 28 & 52 & 3 & 89 & 10 \\
\hline
\end{tabular}

extended over an area of about 240 hectares, and about 140 hectares on the multispectral images.

The multispectral photographs were taken on 18 th July 1978 , between 11.10 and 11.30 hours, from a height of $\mathrm{H}=6,400 \mathrm{mtrs}$, using the $125.20 \mathrm{~mm}$ focal length MKF-6M camera; the scale employed was as 1:50000. Channel 1-4 photographs were made using a Russian-made film T-28; channel 5 and 6 photography on the other hand, proceeded on an infrared-sensitive film I-840. Panchnomatic shots were made at 8.40 hours on 1st August 1978, using an RC-8 Wild photogrammetric camera with focal length of $152.16 \mathrm{~mm}$. Simultaneously, using another RC-10 Wild camera with focal length of $88.26 \mathrm{~mm}$, infrared shots were taken on a Kodak 2,424 film on the 1:51000 scale. Prints of photographs magnified in scale to $1: 10000$ and rephotographed with the Wild cameras, as well as colour compositions made from multispectral shots, were used as the discrimination material. Colour compositions were completed on the additive viewers MSP-4, product of Carl Zeiss Jena, and AC-90, product of the Japanese company NAC.

Table 1 shows that the highest discrimination reliability was that coming from the panchromatic shots (PAN), where the total value of the discrimination reliability factor $\bar{P}_{f}$ for eight crops amounted to $83 \%$, with the total identification error $\bar{B}_{t}$ having been equal to $19 \%$. Accuracy of more or less the same order came from the AC-90 NAC colour compositions, where $\overline{P_{f}}=80 \%$ and $\overline{B_{i}}=7 \%$, and from the MSP-4 compositions, where $\bar{P}_{f}=77 \%$ and $\overline{B_{i}}=26 \%$. The weakest, in this respect, proved to be the infrared photographs (IR), where $\bar{P}_{f}=68 \%$ and $\bar{B}_{i}=30 \%$. This resulted, among other things, from the fact that the infrared shots were lacking contrast and good resolution of details.

Crops with the highest coefficient of discrimination reliability and the smallest identification errors, at the same time, proved to be rye 


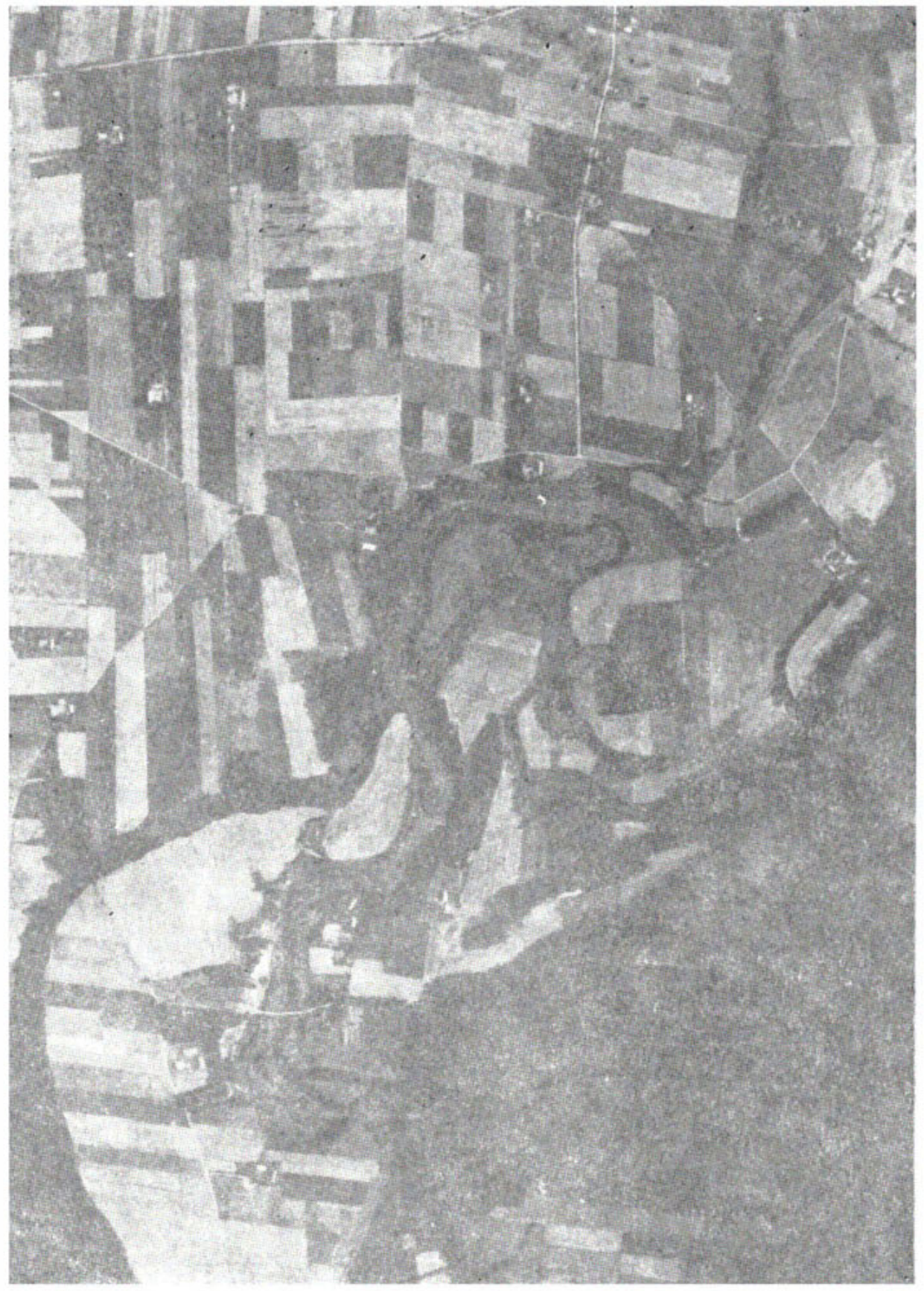

Fig. 2. Fragment of the Plock area of investigation in a 1:15900 panchronatic shot (PAN), August 1978. 
and rape, where $P_{f}$ in the case of rye used to range from $98 \%$ for the panchromatic shots (PAN) to $78 \%$ for the infrared shots (IR) respectively. In the case of rape this coefficient ranged from $95 \%$ on the MSP-4 compositions to $43 \%$ on the IR photographs, the percentages being definitely a significant deviation from the average value. Third comes wheat, where $P_{f}$ was $94 \%$ on the MSP-4 compositions and $75 \%$ on the IR photographs. High errors of identification are found in the case of barley and oats (from $24 \%$ to $42 \%$ and from $36 \%$ to $70 \%$ respectively). These two crops were most frequently mixed up with each other. The coefficient of discrimination reliability ranged from 60 to 70 per cent in this case. Equally poor, if not even worse, was the outcome of discrimination of potatoes and sugar beets. Clover, generally well identifiable on the PAN photographs and AC-90 compositions $\left(P_{t}=80 \%\right.$ and $\left.100 \%\right)$, looked much worse on the IR photographs and MSP-4 compositions. Its varying picture resulted from an irregular growth during the mowing season. For a more clear comparative picture of discrimination reliability for crops photographed from the air see Fig. 1.

Discrimination of crops was carried out by using several types of photographs (PAN, MSP-4, IR) at the same time. Much better discrimination data were achieved, except for air photography of course, as this is evident from Table 1.

To sum up, visual discrimination of crops from air photographs taken at the enid of July, i.e. at the waxy ripeness of corn, gives mixed effects. The best results were those from the discrimination of colour compositions from multispectral photographs and panchromatic photographs; much worse appeared to be those for the infrared photography. Infrared photographs perform better as a complementary material to multispectral and panchromatic shots. It is advisable to use multispectral material for producing other than standard colour-compositions, to strengthen e.g. contrast of crops. Air photographs taken at different dates, hence covering at least two phenological phases, might provide much better results in identifying the whole set of crops. 
